\title{
Band-pass Filter with Harmonics Suppression Capability
}

\author{
Izni Husna Idris ${ }^{1}$, Mohamad Rijal Hamid ${ }^{2}$ Kamilia Kamardin ${ }^{3}$, Mohamad Kamal A Rahim ${ }^{4}$, \\ Farid Zubir ${ }^{5}$, Huda A Majid ${ }^{6}$ \\ ${ }^{1,2,4,5}$ Advance RF and Microwave Research Group (ARFMRG), Faculty of Electrical Engineering, \\ Universiti Teknologi Malaysia, Johor Bahru, Johor, Malaysia \\ ${ }^{3}$ Computer Systems Engineering Group, Advanced Informatics School, Universiti Teknologi Malaysia, \\ Kuala Lumpur, Malaysia \\ ${ }^{3}$ Wireless Communication Centre (WCC), Universiti Teknologi Malaysia, Kuala Lumpur, Malaysia \\ ${ }^{6}$ Research Center for Applied Electromagnetics, Faculty of Electrical and Electronic Engineering, \\ Universiti Tun Hussein Onn Malaysia, Batu Pahat, Johor, Malaysia
}

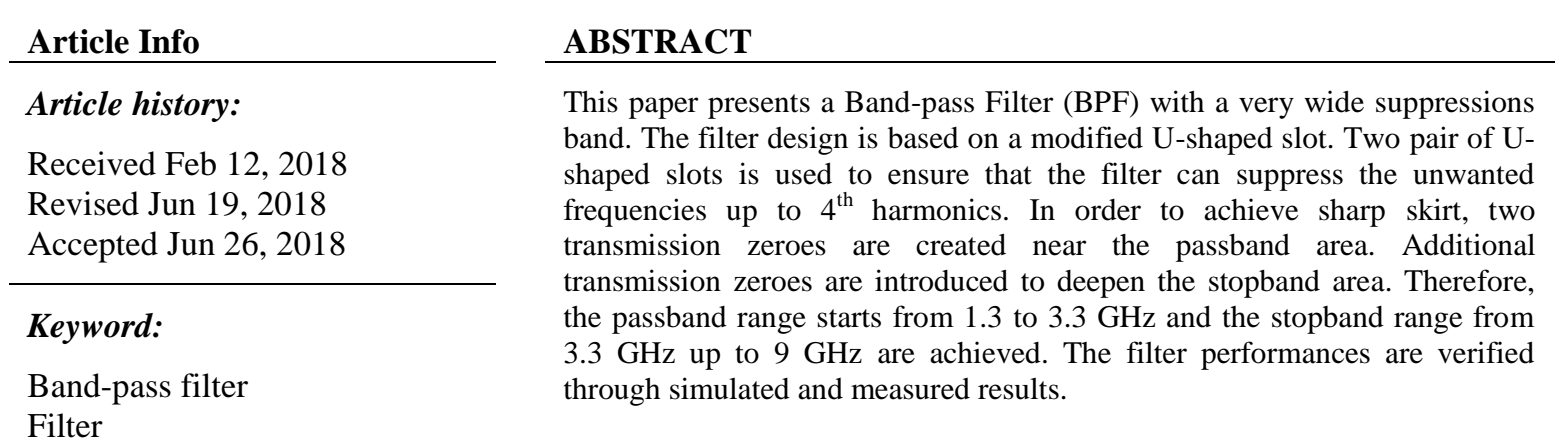

Harmonic suppression

Slot filter

\section{Corresponding Author:}

Izni Husna Idris,

Advance RF and Microwave Research Group (ARFMRG),

Faculty of Electrical Engineering,

Universiti Teknologi Malaysia,

81310 Johor, Malaysia.

Email: husnaidris89@gmail.com

\section{INTRODUCTION}

Many modern communication systems demand multifunctional RF front-end. Multifunctional antenna such as reconfigurable and filtering antennas have the advantage because it can reduce the overall size and complexity in the systems [1]. However, this antenna also exposed to unwanted harmonic frequencies which can cause interference in the communication system. Therefore, filter can be used to remove unwanted frequency by means of being completely eliminated or partially suppressed them.

There are many types of filter can be used as the filtering purposes in the RF front-end. Various filter structures are presented [2]-[13] such as parallel coupled line technique, stepped impedance resonator and multimode resonator.

Filter presented in [2], [3] have dual-band band-pass filter. Filter in [2] consists of symmetrical Y-shaped central-loaded stepped-impedance, overlapped with the hexagon ring resonator. It has a center frequency at $1.9 \mathrm{GHz}$ and $3.4 \mathrm{GHz}$, with the minimum insertion loss results of $0.9 \mathrm{~dB}$ and $1.0 \mathrm{~dB}$, respectively. The simple structure is based on parallel coupled line technique of filter in [3], it has an insertion loss at $2.4 \mathrm{GHz}$ for $-0.6 \mathrm{~dB}$ while at $5 \mathrm{GHz}$ for $-2.1 \mathrm{~dB}$. Filters with more than a quad-band are also been reported in [4]-[5]. By using multimode resonator (MMR), $\lambda / 4$ resonator with mixed electric and magnetic coupling (MEMC), filter in [4] has a quint-band bandpass. Center frequencies are achieved at 2.1 GHz, 3.0 GHz, 4.0 GHz, 4.7 GHz and 7.2 GHz with the insertion loss of $0.98 \mathrm{~dB}, 1.78 \mathrm{~dB}, 1.22 \mathrm{~dB}$, 
$1.77 \mathrm{~dB}$ and $2.39 \mathrm{~dB}$, respectively. However, the more bands the filter has, the more complex structure or design of filters will become.

Ultra-wideband bandpass filter is reported in [6], achieved from $3.1 \mathrm{GHz}$ to $10.6 \mathrm{GHz}$ with minimum insertion loss of $1 \mathrm{~dB}$. The filter consists of $\lambda / 2$ stepped impedance resonator (SIR) with a short stub and two open-circuited stubs loaded. Another filter covers from $1.72 \mathrm{GHz}$ to $3.99 \mathrm{GHz}$ is presented in [7] with the insertion loss of $0.81 \mathrm{~dB}$. The filter is composed of square-loop resonator, three-coupled line load and interdigital feed lines. UWB bandpass filter ranging from $0.5 \mathrm{GHz}$ to $1.9 \mathrm{GHz}$ is achieved in [8]. The filter also has seven transmission zeros which are located from $2.04 \mathrm{GHz}$ to $5.9 \mathrm{GHz}$ with insertion loss greater than $20 \mathrm{~dB}$. A compact bandpass filter with source-load coupling cover from $3.08 \mathrm{GHz}$ to $4.34 \mathrm{GHz}$ [13]. It consists of triple-mode stub-loaded resonator which can generate one odd mode and two even modes. However, this filter has a complex design in order to achieve a wide range of passband and stopband simutanoeusly.

This paper presents a Band-pass Filter (BPF) with a very wide suppressions band. The analysis of the filter which consists of two pairs of modified U-shaped slot is presented. With this structure, the proposed structure is able to have a band-pass from $1.3 \mathrm{GHz}$ to $3.3 \mathrm{GHz}$ and supressed the other unwanted frequencies up to 4th harmonics. To verify the performance, the filter is fabricated and measured. Both of the simulated and measured results are agreed reasonably well, demonstrating that the filter has a good band-pass bandwidth and broadband harmonic suppression.

\section{PARAMETRIC STUDIES FOR FILTER DESIGN}

Harmonic frequencies can somehow contribute to an error and a problem to the wireless communication systems. By integrating a filter to an antenna structure, the harmonic frequencies can be eliminated. There are many designs or shapes of filter introduced from the previous research works. For example; ring-shape, bowtie-shape, square/rectangle-shape and $\mathrm{U} / \mathrm{L} / \Gamma / \pi$-shape are introduced to filtering an antenna frequency. In this paper, a modified U-shaped slot filter with a CPW-fed has been designed.

\subsection{Single-, dual-, triple- and quad-line (s) rectangle-shape of filter}

The forming of modified U-shaped slot is based from rectangle slot. Figure 1 shows a single rectangle-shape slot and was given a name as configuration A. The substrate dimension is $150 \times 100 \mathrm{~mm}^{2}$ (length, $l \mathrm{x}$ width, $w$ ). The single slot denoted as a stub1 has a dimension of length $=l 1$ and width=w $l$, placed in the middle of CPW feedline with $f=3 \mathrm{~mm}$ and $g=0.5 \mathrm{~mm}$. The slot length, $l 1$ is approximately a quarter wavelength at the operating frequency. Thus creating a stop-band function.

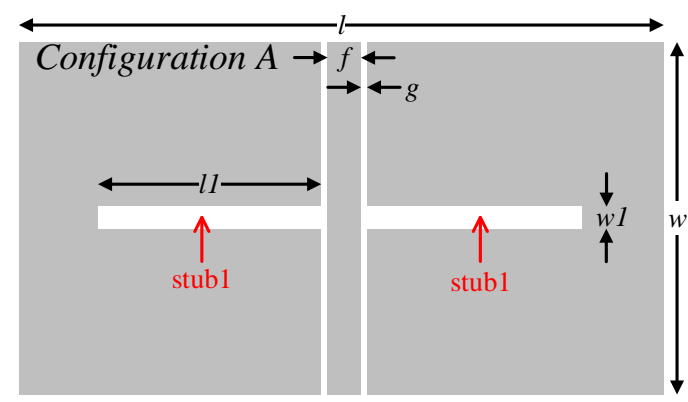

Figure 1. Configuration A - single-line, rectangle slot

Figure 2(a) shows insertion loss $\left(\mathrm{S}_{21}\right)$ results of Configuration A by varying $l 1$ when $w 1$ of stub 1 is fixed at $1 \mathrm{~mm}$. When $l l=9 \mathrm{~mm}$, the $-10 \mathrm{~dB}$ stopband bandwidth is $4.76 \mathrm{GHz}$ to $6.12 \mathrm{GHz}$, with the center frequency, $\mathrm{fc}=5.4 \mathrm{GHz}$. When $l l=10 \mathrm{~mm}$, the bandwidth is covered from $4.21 \mathrm{GHz}$ to $5.65 \mathrm{GHz}$, with fc=4.8 $\mathrm{GHz}$. Bandwidth is ranging from $3.87 \mathrm{GHz}$ to $5 \mathrm{GHz}$ when $l l=11 \mathrm{~mm}$, with $\mathrm{fc}=4.3 \mathrm{GHz}$.

Meanwhile, Figure 2(b) shows $S_{21}$ results when $l 1$ is fixed at $10 \mathrm{~mm}$ and the value of $w l$ is varied from $1 \mathrm{~mm}$ to $5 \mathrm{~mm}$. Bandwidth percentage is increasing from $14.6 \%(w l=1 \mathrm{~mm})$ to $20.8 \%(w l=3 \mathrm{~mm})$ and $24.1 \%(w l=5 \mathrm{~mm})$. From both of the figures, we can notice that if the length of the stub is shorter, the center frequency (fc) is higher as shown in Equation (1). Meanwhile, when the width of the slot is wider, the quality factor becomes lower and thus the bandwidth is increased.

$l \propto 1 / f$ 


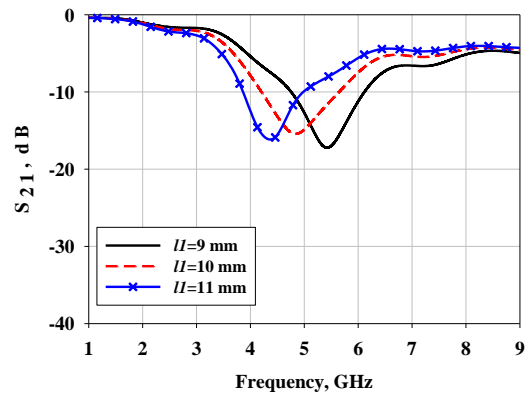

(a)

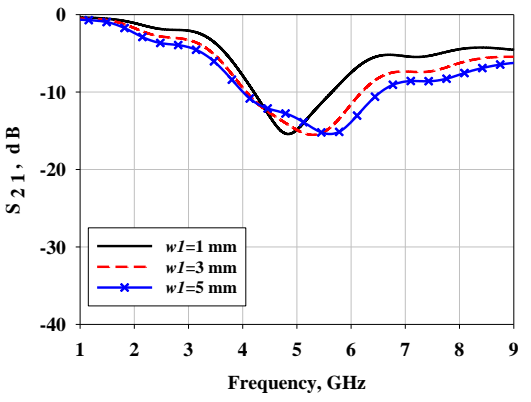

(b)

Figure 2. $\mathrm{S}_{21}$ Results of configuration A when (a) Vary $l 1, w l=1$ (b) Vary $w l, l l=10$

Other rectangle slot shape such as dual-lines, triple-lines and quad-lines are shown in Figure 3, Figure 4 and Figure 5. Dual-lines, rectangle slot as shown in Figure 3(a) consists of two slots known as stub1 and stub2. The structure is given a name as Configuration B. Stub1 has a dimension of $l 1 \times w 1$ while stub2 has a dimension of $l 2 \times w 2$. The distance between stub1 and stub2 is $1 \mathrm{~mm}$. Figure 3(b) shows the insertion loss results of Configuration B when $l l=9 \mathrm{~mm}$ and $l 2=7 \mathrm{~mm}$. Value of $w l$ and $w 2$ is fixed at $1 \mathrm{~mm}$. The lowpass response is achieved from $2 \mathrm{GHz}$ to $5 \mathrm{GHz}$. By adding an additional slot, the stop band frequency range is wider compared to having only one slot. For example, the band-stop is achieved from $4.8 \mathrm{GHz}$ to $6.1 \mathrm{GHz}$ using Configuration A $(l l=9 \mathrm{~mm})$. Meanwhile, by using Configuration B $(l l=9 \mathrm{~mm}, l 2=7 \mathrm{~mm})$, the band-stop covers from $4.9 \mathrm{GHz}$ to $8.0 \mathrm{GHz}$. The introduction of stub2 has helped to create a stopband at higher frequency.

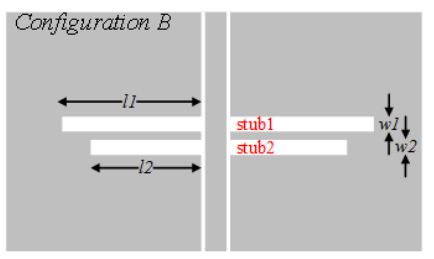

(a)

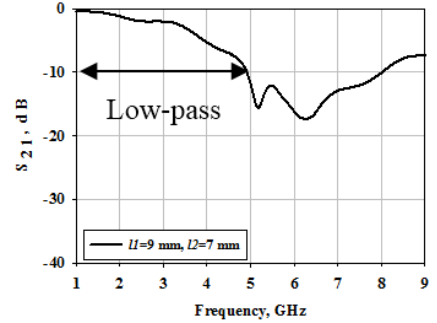

(b)

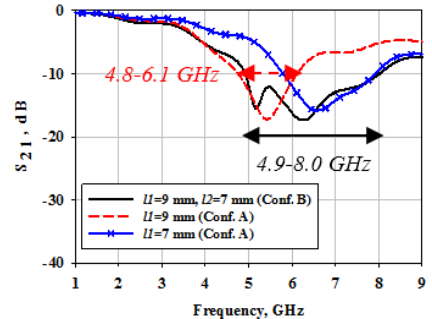

(c)

Figure 3. (a) Configuration B - dual-lines, rectangle slot (b) $\mathrm{S}_{21}$ result when $l 1=9, l 2=7$ (b) $\mathrm{S}_{21}$ result; configuration $\mathrm{B}$ vs configuration $\mathrm{A}$

Figure 4(a) has three stubs where the size of stub1 is $l 1 \times w 1$, stub2 is $l 2 \times w 2$ and stub3 is $l 3 \times w 3$. The structure is denoted as Configuration $C$. The distance between each stub is $1 \mathrm{~mm}$. Figure 4(b) shows the insertion loss result of Configuration $\mathrm{C}$ when $l l=12 \mathrm{~mm}, l 2=9 \mathrm{~mm}, l 3=7 \mathrm{~mm}$. Value of $w l$, w2 and $w 3$ is fixed at $1 \mathrm{~mm}$. With this configuration, the band-stop is now wider which covers from $3.7 \mathrm{GHz}$ to $7.8 \mathrm{GHz}$.

Quad-lines, the rectangle shape shown in Figure 5(a) has one additional stub compared to the triple stub known as stub4. This structure is known as Configuration D. The size of stub 4 is $l 4 \mathrm{x} w 4$. The rest of the stubs are the same as previous Configuration C. The Band-stop from $3.7 \mathrm{GHz}$ to $9.0 \mathrm{GHz}$ is now achieved when $l l=12 \mathrm{~mm}, l 2=9 \mathrm{~mm}, l 3=7 \mathrm{~mm}, l 4=6 \mathrm{~mm}$ as shown in Figure 5(b). Value of $w l, w 2, w 3$ and $w 4$ is fixed at $1 \mathrm{~mm}$. The distance between each stub is $1 \mathrm{~mm}$. Therefore, it can be concluded that when an additional rectangular shape slot is added to the filter structure, multiple stopbands are achieved and the combination of these stopbands make the bandwidth of the band-stop become wider. 


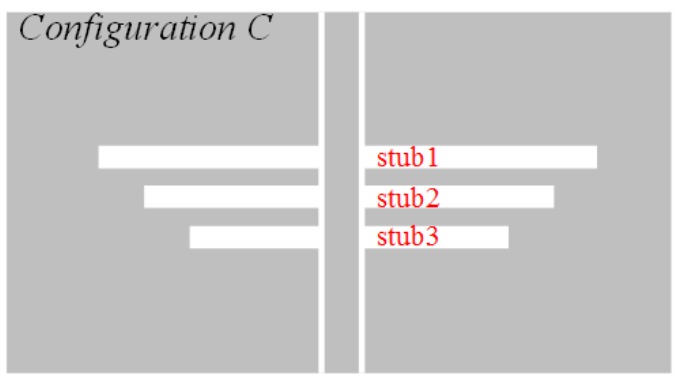

(a)

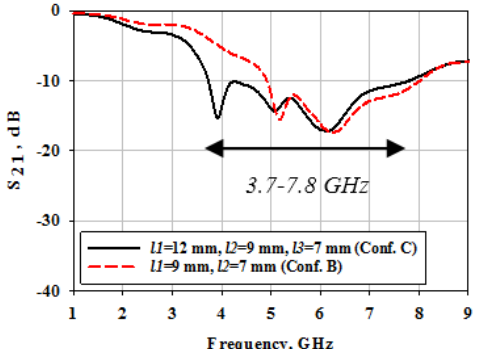

(b)

Figure 4. (a) Configuration $C$ - triple-lines, rectangle slot (b) $S_{21}$ result; configuration $\mathrm{C}$ vs configuration $\mathrm{B}$

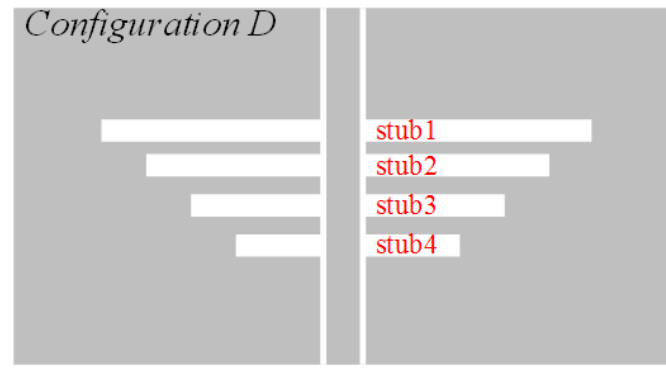

(a)

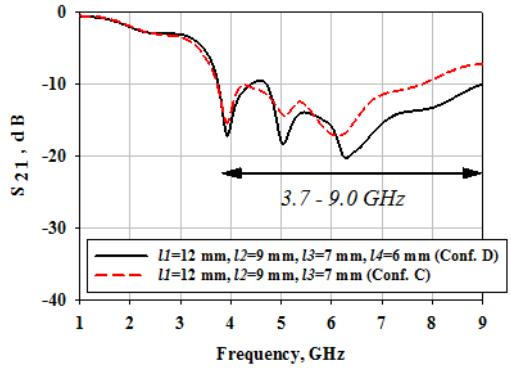

(b)

Figure 5. (a) Configuration D - quad-lines, rectangle slot (b) S21 result; configuration D vs configuration $\mathrm{C}$

\subsection{Combined dual-, triple- and quad-lines rectangle-shape of filter}

Figure 6(a), Figure 6(b) and Figure 6(c) show the combination of dual-, triple- and quad-lines into one unit of the resonator namely Configurations $\mathrm{E}, \mathrm{F}$ and $\mathrm{G}$ respectively. There are two connecting boxes known as boxt and boxr. The dimension of the boxt is $l t \mathrm{x} w t$ while the boxr is $l r \mathrm{x} w r$ as shown in Figure 6(d) and Figure 6(e) respectively. In this paper, the size of the boxt is fixed at $1 \mathrm{~mm} \times 1 \mathrm{~mm}$ while the size of the boxr is fixed at $2 \mathrm{~mm} \times 1 \mathrm{~mm}$, unless it is mentioned otherwise.

Figure 7(a) show the $S_{21}$ result of Configuration $E$ when the length of $l l=9 \mathrm{~mm}$ and $l 2=7 \mathrm{~mm}$ while $w l=w 2=1 \mathrm{~mm}$. The result is compared to Configuration B with the same length of $l 1, l 2, w l$ and $w 2$. By having connecting part, the filter result of Configuration $\mathrm{E}$ is different, even though the length is same as Configuration B. Therefore, to analyze the result obtained in Figure 7(a), both of the rectangular slot length in Configuration B are added by $1 \mathrm{~mm}$. As a result, Configuration E with $l l=9 \mathrm{~mm}$ and $l 2=7 \mathrm{~mm}$ produced quite same bandwidth size with the filter of Configuration B; $l l=10 \mathrm{~mm}$ and $l 2=8 \mathrm{~mm}$. When boxt and boxr is added to the antenna structure, the insertion loss of the filter will produce a slight notch (blue circle) as shown in Figure 7. The notch occurs depending on the distance between each stub (e.g. $w r$ and $w y$ ). The wider the width between the stubs (e.g. distance between stub1 and stub2 or between stub2 and stub3), the smaller the bandwidth of the notch will be produced as shown in Figure 7(c).

The insertion loss result of Configurations $F$ and $G$ are shown in Figure 8. Both of the results are being compared with the same length of stubs but different in configurations. Configuration $\mathrm{F}$ is compared with $\mathrm{C}$ while Configuration $\mathrm{G}$ is compared with $\mathrm{D}$. As expected from Figure 7, results in Figure 8 also have a slight notch coming from the distance between each slot (e.g. $w r$ and $w y$ ). This will prevent the filter to have wide bandwidth for the band-stop. Therefore, Configuration D is the best results so far in term of bandwidth performance. However, the filter requires four pairs of switch to turn on and off the filter later on. 


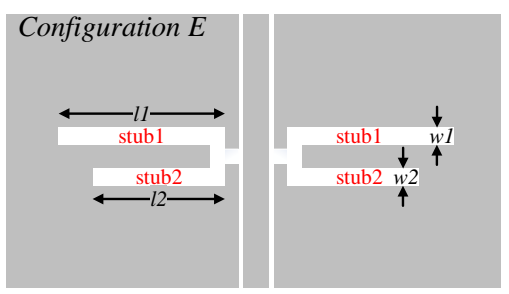

(a)

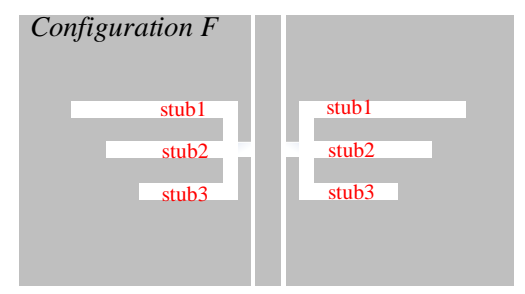

(b)

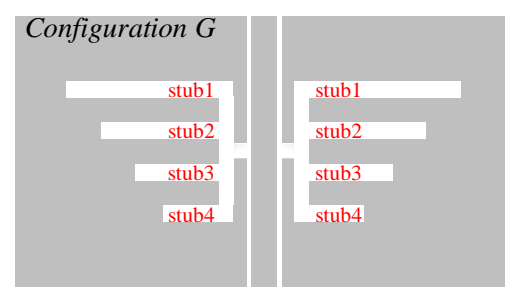

(c)

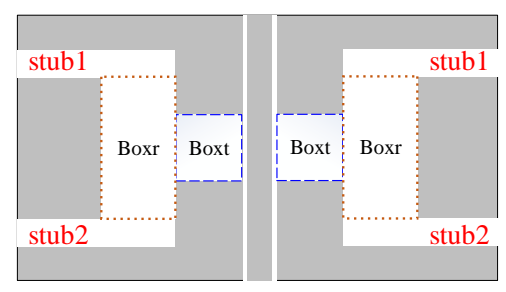

(d)

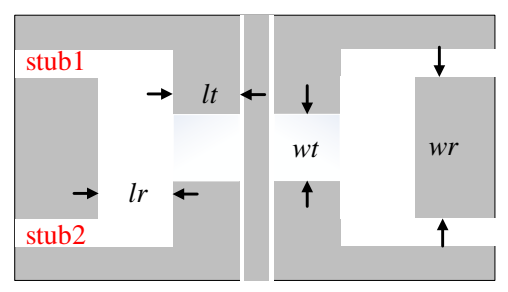

(e)

Figure 6. Combined rectangle slots' shapes (a) Dual-lines (b) Triple-lines (c) Quad-lines (d) Zoom-in boxt and boxr (e) Dimension of boxt and boxr

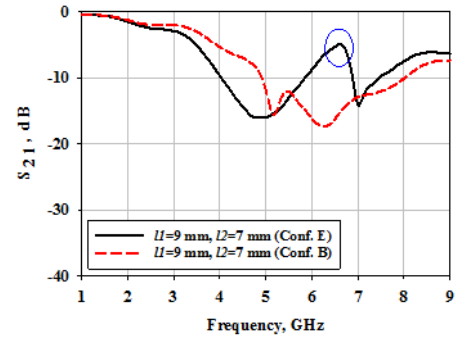

(a)

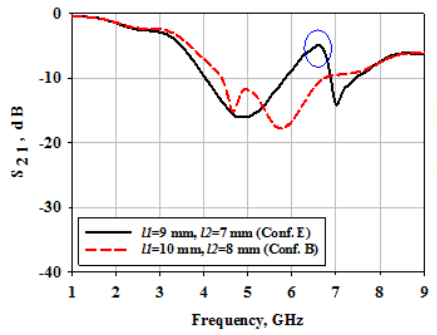

(b)

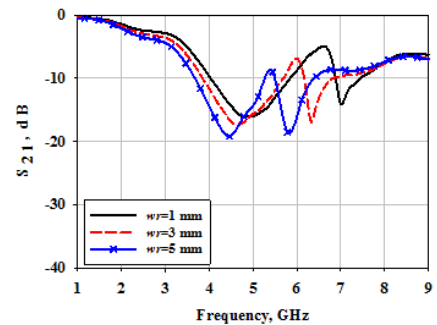

(c)

Figure 7. $S_{21}$ results of (a) Configuration E vs configuration $B$ - same length (b) Configuration E vs configuration $\mathrm{B}$ - different length (c) Configuration $\mathrm{E}(l l=9 \mathrm{~mm}$ and $l 2=7 \mathrm{~mm})$, vary $w r$

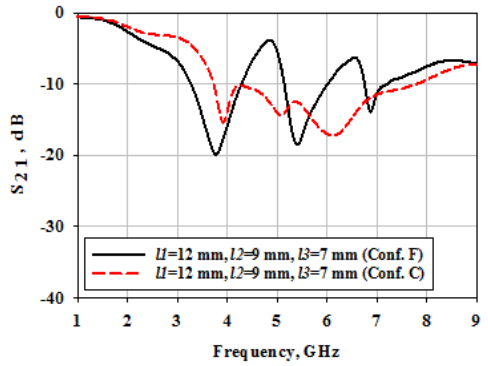

(a)

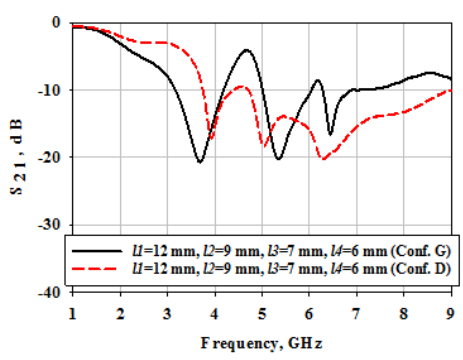

(b)

Figure 8. $\mathrm{S}_{21}$ results of (a) Configuration $\mathrm{F}$ vs configuration $\mathrm{C}$ (b) Configuration $\mathrm{G}$ vs configuration D

\subsection{Other configuration of filter}

In this paper, another possibility of configuration is investigated to achieve a better result in term of the insertion loss, $S_{21}$. For example, a combination of one Configuration $\mathrm{E}$ and one Configuration A will produce the Configuration $J$ as shown in Figure 9(a). Other configuration as shown in Figure 9(b) is a 
combination of one Configuration $\mathrm{E}$ and two Configurations A will produce Configuration K. Lastly, Figure 9(c) is a combination of two units of Configuration E to become a Configuration L. Because of Configuration $\mathrm{L}$ have two units of connecting part, the upper unit of connecting part is known as boxt and boxr while the lower unit is known as boxv and boxy.

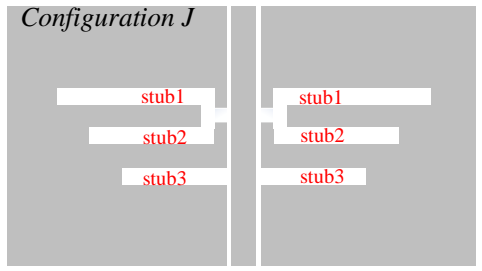

(a)

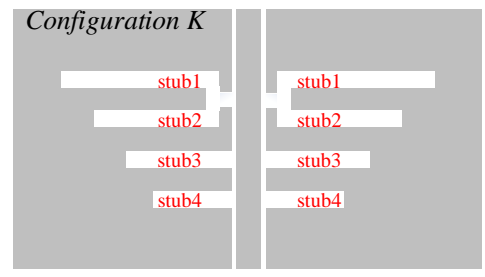

(b)

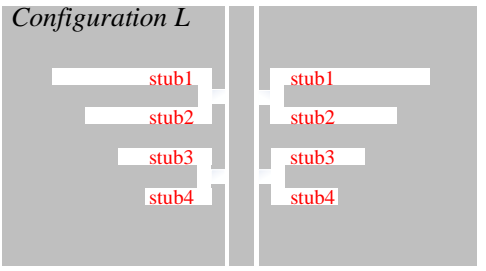

(c)

Figure 9. Rectangle slot shape (a) Combine dual and single-line (b) Combine dual and two single-line (c) Two units of combine dual-lines

Based on Figure 10, we noticed that the Configuration L provide better performance in terms of bandwidth compared to Configuration K. Configuration J, with the size of $l l=12 \mathrm{~mm}, l 2=9 \mathrm{~mm}$ and $l 3=7 \mathrm{~mm}$ have the stopband results from $3.39 \mathrm{GHz}$ to $4.10 \mathrm{GHz}$ and $5.12 \mathrm{GHz}$ to $7.67 \mathrm{GHz}$ as shown in Figure 10 (a). The maximum ratio for Configuration $\mathrm{J}$ is $1.5: 1$.

Configuration K, with the size of $l l=12 \mathrm{~mm}, l 2=9 \mathrm{~mm}, l 3=7 \mathrm{~mm}$ and $l 4=6 \mathrm{~mm}$ has a stopband ranging from $3.44 \mathrm{GHz}$ to $9 \mathrm{GHz}$ with the ratio of 2.62:1 as shown in Figure 10(b). Figure 10(c) shows the stopband result from $3.41 \mathrm{GHz}$ to $9 \mathrm{GHz}$ for Configuration $\mathrm{L}$ with the ratio of 2.64:1. Configuration $\mathrm{L}$ has the same length as Configuration $\mathrm{K}$ but different in shape. Therefore, Configuration $\mathrm{L}$ is chosen because it can provide wider bandwidth and less switch is used compared to Configuration D. The bandwidth of band-stop can be improved by selecting the right length of the rectangular slot shape and the width of the distance between each slot.

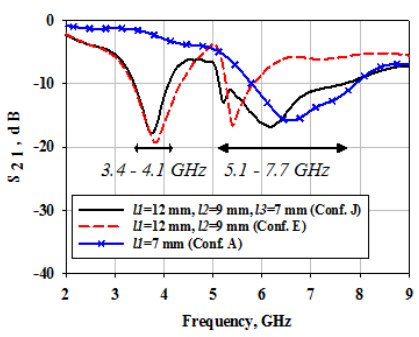

(a)

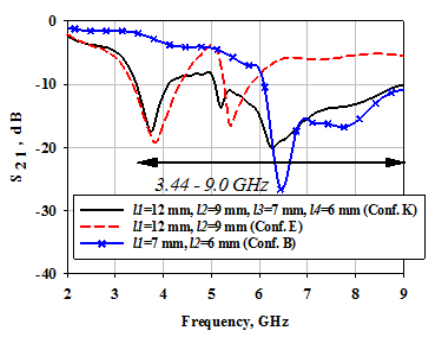

(b)

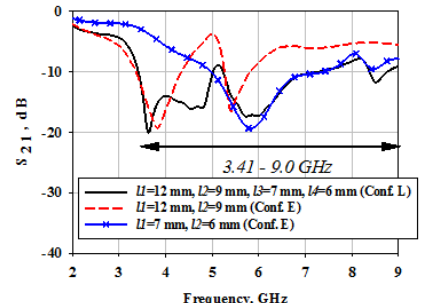

(c)

Figure 10. $\mathrm{S}_{21}$ results of (a) Configuration $\mathrm{J}$ vs configuration $\mathrm{E}$ and configuration $\mathrm{A}$ (b) Configuration $\mathrm{K}$ vs configuration $\mathrm{E}$ and configuration $\mathrm{B}$ (c) Configuration L vs configuration $\mathrm{E}$

\section{FINAL DESIGN OF PROPOSED FILTER}

Figure 11(a) shows the final design of the proposed filters. Zoom-in views of the upper and lower connecting part are shown in Figure 11(b) and Figure 11(c). The dimensions of the filter are listed in Table 1. In this design, the filter should have a band-pass result from $1.5 \mathrm{GHz}$ to $3.0 \mathrm{GHz}$. This is because, the higher order modes will be eliminated when the filter is applied to an antenna structure. Figure 11(d) shows the photograph of the fabricated filter using FR4 substrate with a thickness of $1.6 \mathrm{~mm}$. 


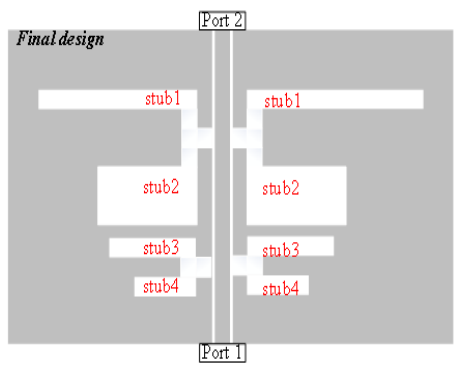

(a)

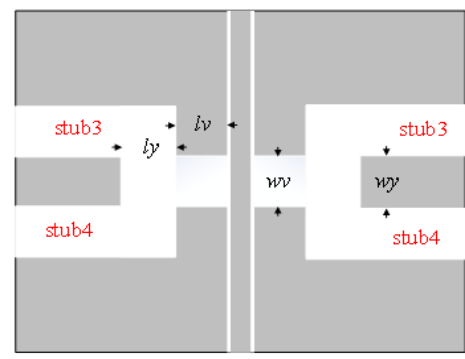

(c)

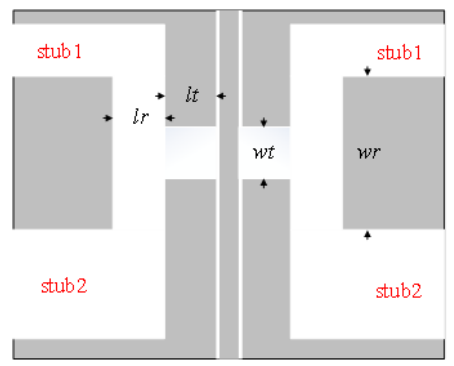

(b)

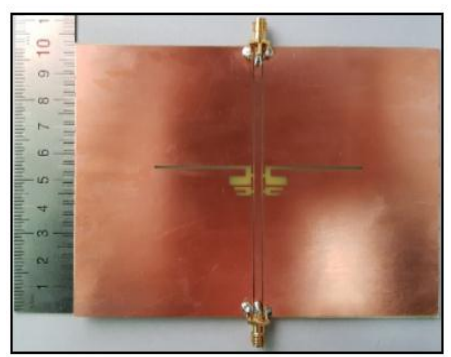

(d)

Figure 11. (a) Final design of the proposed filter (b) Zoom-in view of the upper connecting part (c) Zoomin view of the lower connecting part (d) Photo of the fabricated filter

Table 1. Dimensions of the Final Design

\begin{tabular}{cccccccc}
\hline Parameter & Size $(\mathrm{mm})$ & Parameter & Size $(\mathrm{mm})$ & Parameter & Size $(\mathrm{mm})$ & Parameter & Size $(\mathrm{mm})$ \\
\hline$l$ & 150 & $w$ & 100 & $f$ & 3 & $g$ & 0.5 \\
$l 1$ & 40 & $l 2$ & 9 & $l 3$ & 7 & $l 4$ & 6 \\
$w 1$ & 1 & $w 2$ & 3 & $w 3$ & 1 & $w 4$ & 1 \\
$l t$ & 1 & $l r$ & 2 & $l v$ & 1 & $l y$ & 2 \\
$w t$ & 1 & $w r$ & 3 & $w v$ & 1 & $w y$ & 1 \\
\hline
\end{tabular}

Figure 12 shows the simulated and measured results of the final design of the proposed filter as shown in Figure 11(d). The results show good agreements between simulation and measurement. The insertion loss in Figure 12 shows that the band-pass is measured from $1.35 \mathrm{GHz}$ to $3.31 \mathrm{GHz}$ against that of the simulated result ranging from $1.38 \mathrm{GHz}$ to $3.29 \mathrm{GHz}$. Two transmission zeroes are created near the passband. The $10 \mathrm{~dB}$ rejection band therefore is extended to $9 \mathrm{GHz}$, for both simulated and measured results.

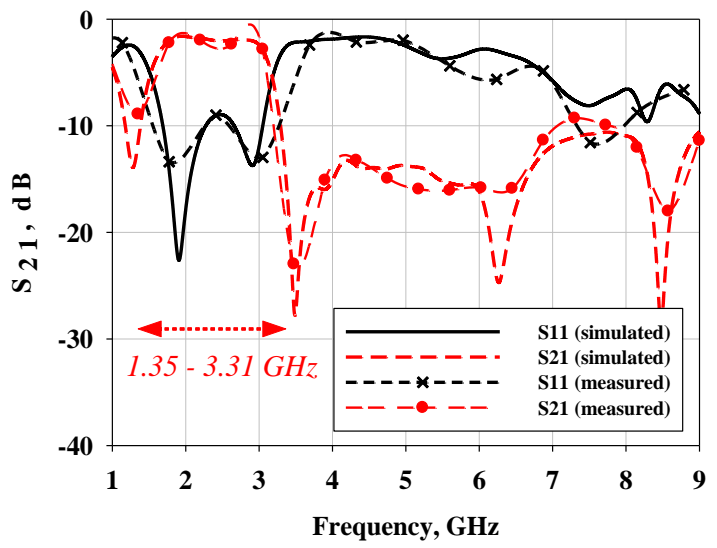

Figure 12. Simulated and measured $S_{11}$ and $S_{21}$ results of the proposed filter 


\section{CONCLUSION}

A new design of band-pass filter with harmonic suppression is presented. The proposed filter is achieved based on connecting two shape of the rectangular-slot into one unit of filter known as a U-shaped slot. By having two pairs of U-shaped slots, the filter has a wider rejection band from $3.33 \mathrm{GHz}$ to $9 \mathrm{GHz}$. The proposed filter shows that it can eliminate the harmonic frequencies effectively.

\section{ACKNOWLEDGEMENTS}

The authors would like to acknowledge the Ministry of Higher Education (MoHE) Malaysia, UTM under the GUP Grant (Q.J130000.2623.14J18) and Advanced RF and Microwave Research Group (ARFMRG) for supporting this work.

\section{REFERENCES}

[1] A. N. Obadiah, et al., "A review on filter-antennas" Applied Mechanics and Materials, vol. 735, pp. 289-293, Feb 2015.

[2] M.-C. Tang and T. Shi, "A novel central-stub-loaded, dual-band bandpass filter for PCS and WiMAX application" IEEE International Microwave Workshop Series on Advanced Materials and Processes for RF and $\mathrm{THz}$ Applications (IMWS-AMP), pp.1-3, 2015.

[3] R. A. Rahim, et. al., "Microstrip dual-band bandpass filter for ISM band applications" IEEE International Conference on Control System, Computing and Engineering, pp. 281-286, 2015.

[4] J. Ai, et. al., "Miniaturized Quint-band bandpass filter based on multi-mode resonator and $\lambda / 4$ resonator with mixed electric and magnetic coupling" IEEE Microwave and Wireless Components Letters, vol. 26, 343-345, 2016.

[5] K.-W. Hsu, et. al., "Compact parallel-coupled sext-band bandpass filter using semi-lumped resonators" IEEE International Microwave Symposium (IMS), pp. 1-4, 2016.

[6] D. Li, et. al., "A novel UWB bandpass filter based on quadruple-mode resonator" IEEE International Wireless Symposium (IWS), pp. 1-3, 2015.

[7] S. Punyawarin and N. Siripon, "A novel wideband bandpass filter using square loop resonator and three-coupled line load, $12^{\text {th }}$ International Conference on Electrical Engineering/Electronics, Computer, Telecommunications and Information Technology (ECTI-CON), pp. 1-4, 2015.

[8] X. Gao, et. al., "Compact ultra-wideband bandpass filter with improved upper stopband using open/shorted stubs" IEEE Microwave and Wireless Components Letters, vol. 27, pp. 123-125, 2017.

[9] S. A. Hamzah, et. al., "Reduced size harmonic suppressed fractal dipole antenna with reconfigurable feature" Proceedings of Asia-Pacific Microwave Conference, pp. 2040-2043, 2010.

[10] F. Darwis, et. al., "Design of compact microstrip U shape bandpass filter using via ground holes" TELKOMNIKA (Telecommunication, Computing, Electronics and Control), vol. 14, pp. 82-85, 2016.

[11] A. Boutejdar, et. al., "Design and improvement of a compact bandpass filter using DGS technique for WLAN and WiMAX Applications" TELKOMNIKA (Telecommunication, Computing, Electronics and Control), vol. 15, pp. 1137-1144, 2017.

[12] D. A. A. Mat, et. al., "Integrated open loop resonator filter designed with notch patch antenna for microwave applications" TELKOMNIKA (Telecommunication, Computing, Electronics and Control), vol. 15, pp. 1485-1492, 2017.

[13] W. Chen, et. al., "Compact and wide upper-stopband triple-mode broadband microstrip BPF" TELKOMNIKA (Telecommunication, Computing, Electronics and Control), vol. 10, pp. 353-358, 2012.

\section{BIOGRAPHIES OF AUTHORS}

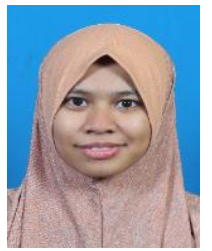

Izni Husna Idris received B. Eng. and M. Eng. degrees in electrical engineering from Universiti Teknologi Malaysia (UTM). Now, she is pursuing the PhD degree in Advanced RF and Microwave Research Group (ARFMRG), UTM Johor, Malaysia. Her research interests include reconfigurable antenna design and multi-function antenna for wireless communication systems application.

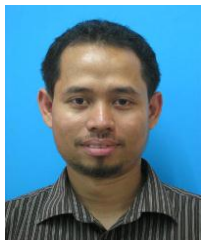

Mohamad Rijal Hamid received the M.Sc. degrees in communication engineering from the Universiti Teknologi Malaysia, Johor Bahru, Malaysia, in 2001 and the PhD degree at the University of Birmingham, Birmingham, U.K. in 2011. He has been with Universiti Teknologi Malaysia (UTM) at the Faculty of Electrical Engineering (FKE), UTM, since 1999. Currently his position is a Senior Lecturer. His major research interest is reconfigurable antenna design for multimode wireless applications. 


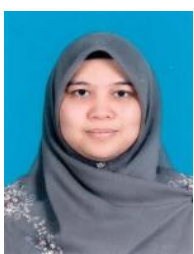

Kamilia Kamardin received her B. Eng. Electronic (Communications) from the University of Sheffield, U.K., in 2004 and obtained her M.Sc. in Information Technology (Data Communications and Networking) from Universiti Teknologi Mara (UiTM), Malaysia in 2007. She received her Ph.D. in Electrical Engineering (Communications) from Universiti Teknologi Malaysia (UTM), Malaysia in 2014. She spent 3 months at University of Bimingham, U.K., as a visiting Ph.D. student. She serves under Computer Systems Engineering Group at Advanced Informatics School. Her research interests include antennas, wireless communication, wearable communication, body centric communication, metamaterials, wireless networking, Internet of Things (IoT) and computer systems engineering.

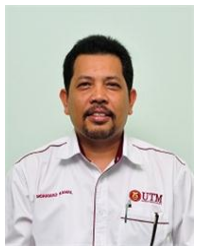

Mohamad Kamal A Rahim received the B Eng. degree in Electrical and Electronic Engineering from University of Strathclyde, UK, in 1987. In 1989, he joined the Department of Communication Engineering, Faculty of Electrical Engineering Universiti Teknologi Malaysia Kuala Lumpur as an Assistant Lecturer A. He obtained his M.Eng Science from University of New South Wales Australia in 1992 and PhD degrees in Electrical Engineering from University of Birmingham UK in 2003. Now he is the Professor in RF and Antenna at Faculty of Electrical Engineering Universiti Teknologi Malaysia. His research interest includes the areas of design of Dielectric resonator antennas, microstrip antennas, small antennas, microwave sensors, RFID antennas for readers and tags, multi-function antennas, microwave cicuits, EBG, artificial magnetic conductors, metamaterials, phased array antennas, computer aided design for antennas and design of millimeter frequency antennas. He has published over 200 articles in journals and conference papers.

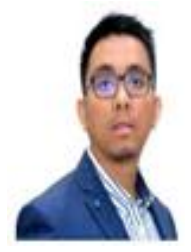

Farid Zubir received the B. Eng. degree in Electrical Engineering majoring in Telecommunication as well as M. Eng. degree (Communication) from the Universiti Teknologi Malaysia in 2008 and 2010 respectively. In 2016, he then obtained his Ph.D degree from the University of Birmingham, UK, for research into direct integration of power amplifiers with antennas in microwave transmitters. He is currently serves as a Senior Lecturer at the Department of Communication Engineering, Faculty of Electrical Engineering, Universiti Teknologi Malaysia. His current research interest and specialization are in the area of RF and Microwave technologies including Planar Array Antennas, Dielectric Resonator Antennas (DRAs), Active Integrated Antenna (AIA), Microstrip Reflectarray Antenna (MRA), Millimeter wave Antennas, Electromagnetic Band Gap (EBG), Artificial Magnetic Conductor (AMC), Full-integrated Transmitting Amplifiers, Linear PAs, Doherty PAs and Bias Decoupling Circuits. He has published over 30 articles in journals, book chapters, conference papers and proceedings.

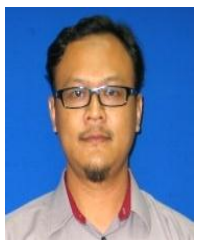

Huda A Majid received his B.Eng Electrical (Telecommunication) in 2007, M.Eng Electrical in 2010 and obtained his PhD Electrical Engineering in 2013 from Universiti Teknologi Malaysia (UTM). He is currently serves as a lecturer at Faculty of Engineering Technology in Universiti Tun Hussein Onn Malaysia (UTHM). His research interest include reconfigurable antenna and metamaterial structures. 